\title{
Optimizing Turmeric Tissue Culture, Testing Different Media and a Plant Growth Regulator Matrix
}

\author{
Toktam Taghavi ${ }^{1}$, Alireza Rahemi ${ }^{1}$, Reza Rafie ${ }^{1}$, and \\ Maru K. Kering ${ }^{1}$
}

\begin{abstract}
AdDitional INDEX words. Curcuma longa, in vitro propagation,
\end{abstract} micropropagation, multiplication, proliferation, regeneration

\begin{abstract}
SUMMARY. Rapid multiplication of turmeric (Curcuma longa) by micropropagation is needed to produce a continuous source of uniformly sized, high-quality, and disease-free plantlets. Three in vitro experiments were conducted to optimize the medium by evaluating nine media and a full factorial combination (matrix) of two plant growth regulators for direct organogenesis of 'Hawaiian Red' turmeric. Two experiments evaluated the media, and the third studied the plant growth regulator matrix. As a result, Driver and Kuniyuki walnut (DKW), Murashige and Skoog (MS), and broadleaf tree basal (BLT) media performed better than woody plant media [Lloyd \& McCown woody plant basal medium (L\&M), and McCown's woody plant basal salt mixture (McCown)] for shoot and root formation. The multiplication rate was 18 plants per explant in DKW with $1 \mathrm{mg} \cdot \mathrm{L}^{-1}$

6-benzylaminopurine (BAP) and $0.1 \mathrm{mg} \cdot \mathrm{L}^{-1} 1$-naphthaleneacetic acid (NAA). After transferring the plants to an ex vitro environment, the survival rate was $97 \%$, and $30 \%$ higher than previously reported. DKW produced the highest number of plantlets (with shoots and roots), and BLT produced fewer plants with higher biomass. In the MS media, higher BAP to NAA ratio $\left(2.5\right.$ to $\left.0.1 \mathrm{mg} \cdot \mathrm{L}^{-1}\right)$ produced the most significant number of shoots; however, the lowest concentration of BAP and NAA $\left(0.1 \mathrm{mg} \cdot \mathrm{L}^{-1}\right.$ of both) produced the highest number of rooted plantlets. There are two recommendations for tissue culture of 'Hawaiian Red' turmeric. To produce the highest number of plantlets, one should use the higher BAP to NAA ratio $\left(2.5 \mathrm{mg} \cdot \mathrm{L}^{-1} \mathrm{BAP}\right.$ and $\left.0.1 \mathrm{mg} \cdot \mathrm{L}^{-1} \mathrm{NAA}\right)$ for shoot proliferation and then transfer the explants to the root initiation media. However, to reduce the number of subcultures, the explants can be grown in the lowest concentration of both BAP and NAA $\left(0.1 \mathrm{mg} \cdot \mathrm{L}^{-1}\right)$ to induce both shoot and root. Although, the number of plantlets (with roots and shoots) will decrease in this method, there is no need for subsequent subcultures and changing of the plant growth regulator combinations.
\end{abstract}

$\mathrm{T}$ Turmeric [Curcuma longa (formerly $C$. domestica) $]$ is a herbaceous evergreen plant in the Zingiberaceae family (Sugaya, 1992). The turmeric genus (Curcuma) includes about 50 species found in tropical and subtropical regions (Sugaya, 1992). Curcuminoids, and mainly curcumin, are potential pharmaceutical

Received for publication 14 May 2021. Accepted for publication 12 Aug. 2021.

Published online 27 October 2021.

${ }^{1}$ College of Agriculture, Virginia State University, 1 Hayden Drive, Petersburg, VA 23806

This article is a contribution of the Virginia State University, Agricultural Research Station (Journal Article Series Number 376).

T.T. is the corresponding author. E-mail: ttaghavi@ vsu.edu.

This is an open access article distributed under the CC BY-NC-ND license (https://creativecommons. org/licenses/by-nc-nd/4.0/).

https://doi.org/10.21273/HORTTECH04890-21 compounds in turmeric genus $(\mathrm{Wu}$ et al., 2015). The number of natural food products containing turmeric jumped $14 \%$ in 2016 compared with 2014, and beverages containing turmeric (i.e., turmeric latte) increased by 77\% (Gupta et al., 2013). Curcumin, the active substance of turmeric, has multiple therapeutic properties, such as anti-inflammatory and antioxidant properties, and cancer prevention.

The United States is one of the major turmeric importing countries, and the demand for turmeric has increased tremendously in the last 5 years. The United States imported \$35 million worth of turmeric in 2017, up from \$2.5 million 15 years ago. The global curcumin market is expected to grow from $\$ 56.23$ million in 2017 to $\$ 114.34$ million by 2025 at a cumulative annual growth rate of $9.28 \%$ during the forecast period 2018-25, according to the new report published by Fior Markets (Globe Newswire, 2020).

India is the major producer and exporter of turmeric in the world (Sasikumar, 2005), with a production of close to 783,318 t from about 261,900 ha. India exported $133,600 \mathrm{t}$ of turmeric (\$190.3 million) in 2019 (Indian Spice Board Statistics, 2020). Although turmeric production has been growing in the United States, it cannot keep up with demand, and so the majority of turmeric in the United States is imported from India (Kyger, 2019).

Since turmeric is a triploid plant $(2 n=3 x=63)$, interspecific hybridization is ineffective in most cases, and genetic improvement is often limited to germplasm selection and mutations (Ravindran et al., 2007). Flowering in turmeric is rare, flowers are sterile, and the seed set does not occur (Sasikumar, 2005; Verma et al., 2018). Therefore, turmeric is commercially propagated through "rhizome division," a timeconsuming vegetative propagation method with a very low multiplication rate.

Also, rhizome propagation has other limitations such as expensive field maintenance, as well as turmeric's high susceptibility to rhizome rot diseases (Khader et al., 1994; Shagufta et al.,

\begin{tabular}{llll}
\hline $\begin{array}{l}\text { Units } \\
\text { To convert U.S. to SI, } \\
\text { multiply by }\end{array}$ & U.S. unit & Sl unit & $\begin{array}{l}\text { To convert SI to U.S., } \\
\text { multiply by }\end{array}$ \\
\hline 0.4047 & acre $(\mathrm{s})$ & $\mathrm{ha}$ & 2.4711 \\
29,574 & $\mathrm{fl} \mathrm{oz}$ & $\mu \mathrm{L}$ & $3.3814 \times 10^{-5}$ \\
29.5735 & $\mathrm{fl} \mathrm{oz}$ & $\mathrm{mL}$ & 0.0338 \\
2.54 & inch $(\mathrm{es})$ & $\mathrm{cm}$ & 0.3937 \\
25.4 & inch $(\mathrm{es})$ & $\mathrm{mm}$ & 0.0394 \\
28.3495 & $\mathrm{oz}$ & $\mathrm{g}$ & 0.0353 \\
0.001 & $\mathrm{ppm}$ & $\mathrm{g} \cdot \mathrm{L}^{-1}$ & 1000 \\
1 & $\mathrm{ppm}$ & $\mathrm{mg} \cdot \mathrm{L}^{-1}$ & 1 \\
1 & $\mathrm{ppm}$ & $\mu \mathrm{L} \cdot \mathrm{L}^{-1}$ & 1 \\
0.0703 & $\mathrm{psi}$ & $\mathrm{kg} \cdot \mathrm{cm}^{-2}$ & 14.2233 \\
0.9072 & ton $(\mathrm{s})$ & $\mathrm{t}$ & 1.1023 \\
$\left({ }^{\circ} \mathrm{F}-32\right) \div 1.8$ & ${ }^{\circ} \mathrm{F}$ & ${ }^{\circ} \mathrm{C}$ & $\left({ }^{\circ} \mathrm{C} \times 1.8\right)+32$
\end{tabular}


2009). Turmeric is vulnerable to a number of fungal diseases, with the rhizome rot being the most destructive one, causing enormous economic damage. Pythium is the predominant organism actively involved in the rhizome rot disease followed by Rhizoctonia and Fusarium. Crop loss up to $50 \%$ has been reported due to rhizome rot in areas with large-scale production in India (Anoop et al., 2014). The fungus also can survive in diseased rhizomes kept for planting.

The slow multiplication rate (annually 5-to 10-fold) has limited the availability of high-yielding genotypes. Tissue culture techniques allow for rapid clonal propagation of turmeric plants to mitigate the problems: low multiplication rates and disease issues (Shirgurkar et al., 2001). Tissue culture ensures a continuous source of highquality, disease-free, and true-to-type plantlets to enhance potential crop productivity (Bhabha Atomic Research Centre, 2020; Sinchana et al., 2020).

The multiplication of turmeric and its related species under in vitro conditions has been widely studied. There are reports for turmeric tissue culture from 1978 (Nadgauda et al., 1978) up to 2020 (Bhabha Atomic Research Centre, 2020; Sinchana et al., 2020) using different tissues/ organs, explants, and media with different plant growth regulators (PGRs) concentrations. Some researchers used the Murashige and Skoog (MS) medium as the base and changed the PGRs combinations and concentrations. A review listed full-strength MS as the primary medium (Prabhakaran Nair, 2013), but others have also been tested [half-strength MS (Sit and Tiwari, 1996), Lloyd \& McCown woody plant basal (L\&M) medium (Nasirujjaman et al., 2005), Smith medium (Nadgauda et al., 1978), Ringe and Nitsch medium (Mukhri and Yamaguchi, 1986), Linsmaier and Skoog (LS) medium (Gayatri et al., 2005), or Gamborg's B-5 basal medium (Ma and Gang, 2006)]. Yet, in these trials, the MS medium was not used as a control, making comparisons impossible.

Other media components such as PGRs and vitamins also affect plant regeneration and multiplication rate. PGRs, including 6-benzylaminopurine (BAP), 1-naphthalene acetic acid (NAA), and 6-furfurylamino purine [kinetin (KT)], are commonly used by most researchers for micropropagation (Panda et al., 2007). BAP is the most preferred PGRs for shoot elongation and multiplication, and NAA is generally known to promote rooting. Some investigators used a combination of BAP and NAA, benzyladenine (BA), and NAA (Ghosh et al., 2013), while some used a combination of KT and BAP or KT and NAA (Mohanty et al., 2010).

The objectives of this study were to optimize the medium by comparing nine different media and to select 1) the best medium for shoot and root regeneration of turmeric and 2) the best PGRs combinations using a matrix of four BAP and four NAA concentrations.

\section{Material and methods}

'Hawaiian Red' turmeric rhizome pieces were planted at Virginia State University (VSU) Research Randolph farm (Rafie and Mullins, 2017) under high tunnel conditions. Rhizome pieces $(1-2 \mathrm{~cm})$ were excised, and surface sterilized by soaking in ethanol $70 \%$ (BP8201500; Fisher Scientific, Waltham, MA) and $100 \mu \mathrm{L}$ of polysorbate 20 surfactant (Tween 20, BP337; Fisher Scientific) for $10 \mathrm{~min}$, then washed two times with sterile distilled water, soaked in $10 \%$ bleach $(7.55 \%$ sodium hypochlorite; Clorox Oakland, CA) for $10 \mathrm{~min}$, and then washed three times with sterile distilled water. The meristems $(0.5-1 \mathrm{~mm})$ were cultured in vitro in MS medium [M0404; SigmaAldrich, St. Louis, MO (Table 1)] with a $\mathrm{pH}$ of $5.7 \pm 1$ supplemented with 30 g. $\mathrm{L}^{-1}$ sucrose (MP-190271, Fisher Scientific), $8 \mathrm{~g} \cdot \mathrm{L}^{-1}$ agar (BP1423-2, Fisher Scientific), $1 \mathrm{mg} \cdot \mathrm{L}^{-1}$ BAP (30631005; Plantmedia, Dublin, $\mathrm{OH}), 0.1 \mathrm{mg} \cdot \mathrm{L}^{-1}$ NAA (N0640, Sigma-Aldrich), and $100 \mu \mathrm{L} \cdot \mathrm{L}^{-1}$ plant preservative mixture [PPL33; Cassion Laboratories, Smithfield, UT (Table 2)].

This study was conducted to optimize the medium by evaluating nine media and the PGRs matrix for direct organogenesis of turmeric. These nine media were chosen because they are readily available at a reasonable cost to tissue culture laboratories, and some are designed for woody plants. In the first two experiments, nine different media were categorized into four groups: 1) broadleaf tree basal (BLT), 2) Driver and Kuniyuki walnut (DKW), 3) L\&M and McCown have the same formulation and were designed for woody plants by Lloyd and McCown (1981), and 4) MS medium. MS (M0404) and DKW were chosen as benchmarks and were used in both experiments. The third experiment studied turmeric growth and development in a PGRs matrix $(4 \times 4$ concentrations $)$ of BAP and NAA. A single explant (clone) was used for this study to avoid any differences that may exist within explants. Due to the limited number of the explants at a given time, three separate experiments were designed.

The first experiment was conducted in jars $(220 \mathrm{~mL})$. The media were premixed, dispensed into jars, and then sterilized in the autoclave. The second and third experiments were conducted in $50-\mathrm{mL}$ culture tubes. The media were premixed, sterilized, and then dispensed into the sterile $25 \times 150-\mathrm{mm}$ polycarbonate culture tubes under aseptic conditions at a horizontal laminar flow hood.

The autoclave for all steps was set for $20 \mathrm{~min}$ at $121^{\circ} \mathrm{C}$ and $1.2 \mathrm{~kg} \cdot \mathrm{cm}^{-2}$ of pressure. The cultures were incubated at a temperature of $23 \pm 2{ }^{\circ} \mathrm{C}$, under constant light (light intensity of 20-25 $\left.\mu \mathrm{mol} \cdot \mathrm{m}^{-2} \cdot \mathrm{s}^{-1}\right)$ provided by lightemitting diodes [LEDs, (Habitats, Santa Fe, NM)] with a mixture of white, red, blue, and green at a ratio of 10:3: $2: 2$, respectively). This growing condition was used for all three experiments. The organs (both shoot and root) were induced, and the callus stage was avoided.

EXPT. 1: EVALUATION OF DIFFERENT MEDIA IN JARS. The proliferated shoot explants of three different sizes [(small: no developed organ; medium: shoot with tiny leaves; large: shoot with one developed leaf), Fig. 1] were subcultured into five different media: 1) DKW (D-6162; PhytoTech Laboratories, Lenexa, KS), 2) McCown's woody plant basal salt mixture (McCown, M6774; Sigma-Aldrich), 3) MS basal medium with Gamborg's vitamins (M0 404), 4) MS basal medium (M5519, Sigma-Aldrich), and 5) MS basal salt mixture [M5524, SigmaAldrich (Table 1). We used three jars as three replicates with three explants in each jar as subsamples for each medium tested. The Eagle's minimum essential medium (MEM) vitamin $100 \times$ solution (M6895, Sigma-Aldrich) was added to the ones that did not have vitamins in 


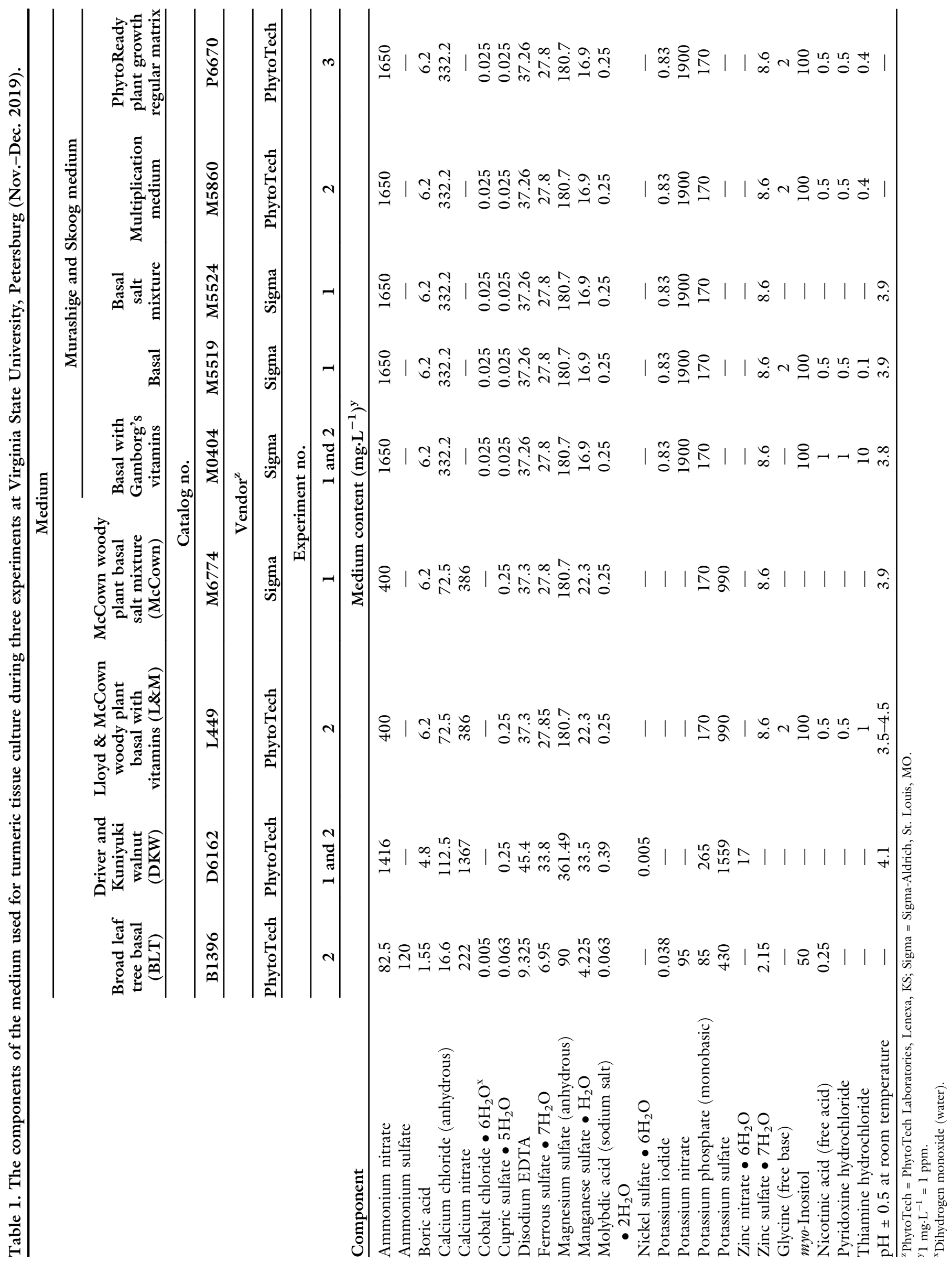




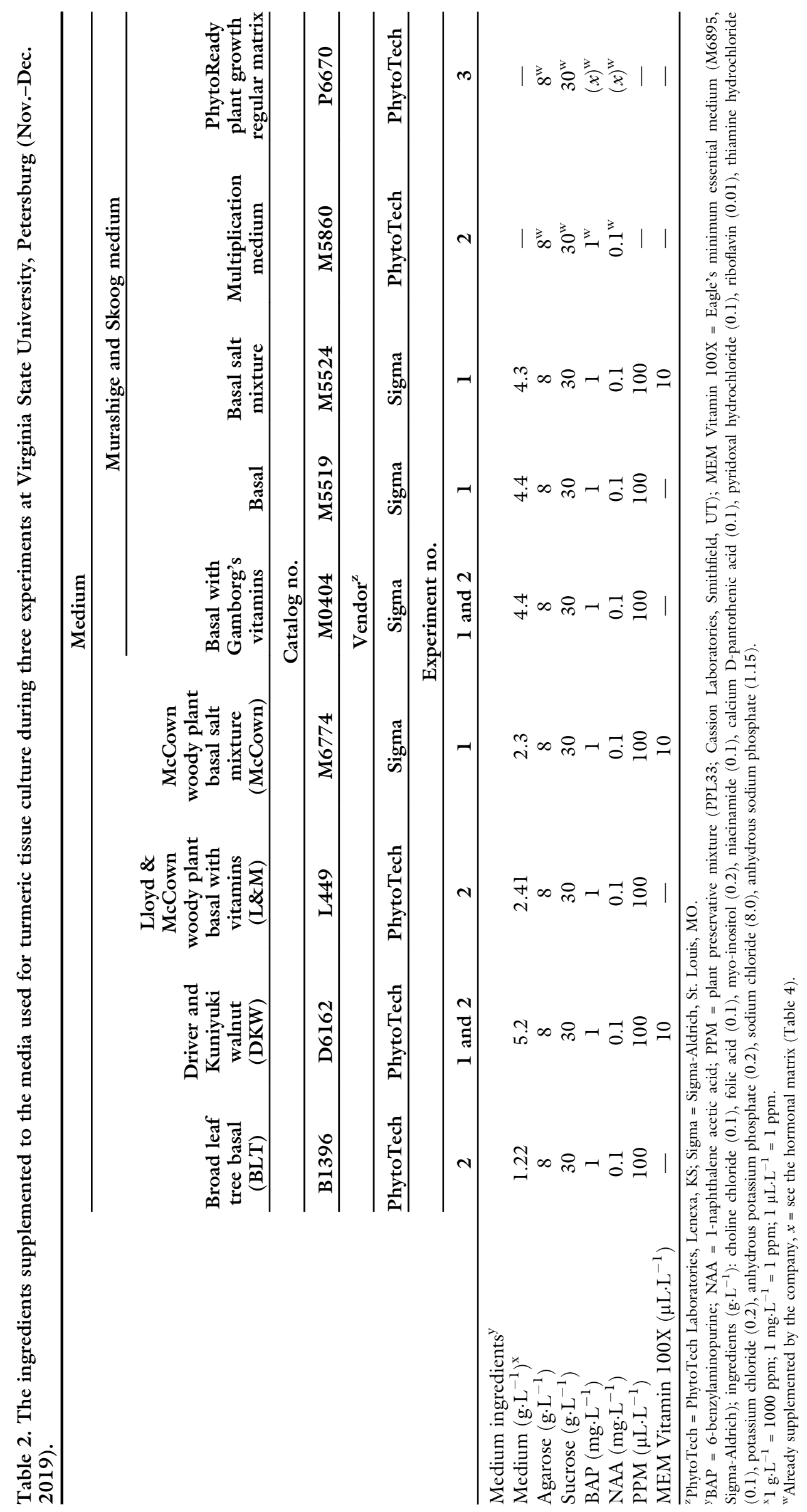


Table 3. Formula of PhytoReady media (P6670, PhytoReady plant growth regulator matrix medium; PhytoTech Laboratories, Lenexa, KS) used for turmeric tissue culture at Virginia State University, Petersburg, during Nov.-Dec. 2019 (third experiment; evaluation of plant growth regulator matrix).

\begin{tabular}{|c|c|c|c|}
\hline Medium content & $\begin{array}{c}\text { Concn } \\
\left(\mathrm{mg} \cdot \mathrm{L}^{-1}\right)^{\mathrm{z}}\end{array}$ & Medium content & $\begin{array}{c}\text { Concn } \\
\left(\mathrm{mg} \cdot \mathrm{L}^{-1}\right)\end{array}$ \\
\hline Ammonium nitrate & 1,650 & Potassium iodide & 0.83 \\
\hline Agar (micropropagation grade) & 8,000 & Potassium nitrate & 1,900 \\
\hline Boric acid & 6.2 & Potassium phosphate (monobasic) & 170 \\
\hline Calcium chloride (anhydrous) & 332.2 & Zinc sulfate $\bullet 7 \mathrm{H}_{2} \mathrm{O}^{\mathrm{y}}$ & 8.6 \\
\hline Cobalt chloride $\bullet 6 \mathrm{H}_{2} \mathrm{O}$ & 0.025 & Glycine (free base) & 2 \\
\hline Ferrous sulfate $\bullet 7 \mathrm{H}_{2} \mathrm{O}$ & 27.8 & Pyridoxine hydrochloride & 0.5 \\
\hline Magnesium sulfate (anhydrous) & 180.7 & Sucrose & 30,000 \\
\hline Manganese sulfate $\bullet \mathrm{H}_{2} \mathrm{O}$ & 16.9 & Thiamine hydrochloride & 0.1 \\
\hline Molybdic acid (sodium salt) $\bullet 2 \mathrm{H}_{2} \mathrm{O}$ & 0.25 & Benzylaminopurine and 1- naphthalene acetic acid & (matrix table) \\
\hline
\end{tabular}

${ }^{\mathrm{z}} \mathrm{l} \mathrm{mg} \cdot \mathrm{L}^{-1}=1 \mathrm{ppm}$.

${ }^{y}$ Dihydrogen monoxide (water).

their formula [DKW, McCown, and MS basal salt mixture (Tables 1 and 2)].

The 220-mL culture jars (C1770, PhytoTech Laboratories) had standard closures (C070, PhytoCap, CultureJar; PhytoTech Laboratories) for all media, except for McCown. Both standard and filtered closures (C176, Closure, PhytoCap Vented; PhytoTech Laboratories) were used for this medium. Filtered caps (ventilated) facilitate gas exchange, reduce ethylene build-up that stunts plant growth, and reduce condensation. There are reports that ventilation has benefited the plant growth in tissue culture systems (Nowak and Pruski, 2004). Due to the limited number of explants and to reduce the workload, we randomly used one medium $(\mathrm{Mc}-$ Cown) to test if the plant growth would benefit from facilitated gas exchange and less condensation.

All jars were placed under the same temperature and light conditions, as mentioned above. The explants' weights were calculated by the difference between the jars' weights before and after adding the explants. Four weeks after subculture, the weights of the jars and the explants (grams), and number of leaves (total number of expanded leaves in each explant) were recorded (Fig. 2). Jars were placed against a grid, and diameter (largest dimension of explant in millimeters), and height (height from the lowest point of the crown to the highest point of the explant in millimeters) were measured. Eight weeks after subculture, the explants were harvested (Fig. 3), and the number of shoots (shoot primordia without roots) and plantlets (shoots with roots), plant weight (grams), and height (millimeters) were measured. In this paper, plantlets were used for complete but small plants, which had both shoots and roots, and shoots were used when the roots have not formed yet. The shoots were as small as single primordia or could have one or more leaves, but no root or root primordia were formed. Plant vigor was scored based on the height of the tallest plant in the jar as $\mathrm{l}=\mathrm{l}-20 \mathrm{~mm} ; 2=2 \mathrm{l}-40$ $\mathrm{mm} ; 3=41-60 \mathrm{~mm} ; 4=61-80 \mathrm{~mm}$, and $5=$ more than $80 \mathrm{~mm}$ (Fig. 2).

EXPT. 2: Evaluation OF DIFFERENT MEDIA IN CULTURE TUBES. In the second experiment, the explants with small sizes were selected, and one explant was subcultured into $50-\mathrm{mL}$ tubes with five different media. The media were 1) BLT medium (B1396, PhytoTech Laboratories), 2) DKW, 3) L\&M medium with vitamins (L449, PhytoTech Laboratories), 4) M0404, and 5) PhytoReady MS Multiplication Medium [M5860, PhytoTech Laboratories (Table 1)]. There was one explant in each tube, and a minimum of 20 replicate culture tubes (Fig. 4) for each medium tested. The MEM was added to DKW and McCown because they lacked the necessary multivitamins (Table 2). The tubes were placed under the same temperature and light conditions. The explant's weight (grams) was calculated by differences between the tubes before and after planting the explants. The explant occupied the tube space for 4 weeks, but plant growth characteristics were not measurable. Therefore, explants were harvested 8 weeks after planting, and the following growth characteristics were measured; plant biomass (fresh weight gain in grams), highest height (millimeters), the number of shoots (shoot or shoot primordia without roots) and plantlets (shoots with roots).

EXPT. 3: Evaluation OF Plant GROWTH REgULATOR MATRIX. The explants with small sizes were selected. Each explant was subcultured in PhytoReady tubes (P6670, PhytoReady plant growth regulator (PGR) matrix medium; PhytoTech Laboratories). The PGR matrix tubes contained the macro- and-micronutrients and vitamins (Table 3), as described by Murashige and Skoog (1962). They were supplemented with combinations of four concentrations of $\operatorname{BAP}(0.0,0.1$, 1.0 , and $2.5 \mathrm{mg} \cdot \mathrm{L}^{-1}$ ) and four concentrations of NAA $(0.0,0.1,1.0$, and $2.5 \mathrm{mg} \cdot \mathrm{L}^{-1}$ ) (Table 4). The matrix included 16 treatments and five replicates, which were premixed, sterilized, and dispensed into $25 \times 150-\mathrm{mm}$ polycarbonate culture tubes and made ready for subculture.

After the explants were subcultured, the explant diameter (millimeters), height (millimeters), number of shoots, leaves, and roots, and weight [difference between culture tube before and after subculture (grams)] were recorded. The cultures were harvested 4 weeks later, and all traits were measured again in addition to the aerial root numbers. Shoot proliferation was also scored based on the height of the growth in the culture tube $[1=1-10 \mathrm{~mm}, 2=11-20$ $\mathrm{mm}, 3=2 \mathrm{l}-30 \mathrm{~mm}, 4=31-40 \mathrm{~mm}$, and $5=41-50 \mathrm{~mm}$ (Figs. 5 and 6 )]. The differences between characteristics 
Table 4. Plant growth regulator matrix of the PhytoReady media (P6670; PhytoTech Laboratories, Lenexa, KS) including four concentrations of 1-naphthalene acetic acid (NAA) and four concentrations of 6-benzylaminopurine (BAP) with their media code, used for turmeric tissue culture experiment was conducted at Virginia State University, Petersburg, during Nov.-Dec. 2019 (third experiment; evaluation of plant growth regulator matrix).

\begin{tabular}{lccccc}
\hline & & \multicolumn{4}{c}{ BAP concn $\left(\mathbf{m g} \cdot \mathrm{L}^{-1}\right)^{\mathbf{z}}$} \\
\cline { 3 - 6 } Concn and combination & & $\mathbf{0}$ & $\mathbf{0 . 1}$ & $\mathbf{1 . 0}$ & $\mathbf{2 . 5}$ \\
\hline NAA concn $\left(\mathrm{mg} \cdot \mathrm{L}^{-1}\right)$ & 0 & $\mathrm{~A}$ & $\mathrm{~B}$ & $\mathrm{C}$ & $\mathrm{D}$ \\
& 0.1 & $\mathrm{E}$ & $\mathrm{F}$ & $\mathrm{G}$ & $\mathrm{H}$ \\
& 1.0 & $\mathrm{I}$ & $\mathrm{J}$ & $\mathrm{K}$ & $\mathrm{L}$ \\
& 2.5 & $\mathrm{M}$ & $\mathrm{N}$ & $\mathrm{O}$ & $\mathrm{P}$ \\
\hline
\end{tabular}

${ }^{\mathrm{z}} \mathrm{lmg} \cdot \mathrm{L}^{-1}=1 \mathrm{ppm}$.

measured at planting and after 4 weeks were used for data analysis.

At the end of each experiment, three plantlets from each treatment of all experiments were transferred to plug trays $(2 \times 2$ inches $)$ with potting mix (Pro-Mix BX; Premier Tech Horticulture, Rivière-du-Loup, QC, Canada), moved to a growth chamber with gradually decreasing humidity from $95 \%$ to $65 \%$ over 2 weeks. Plants were then transplanted into 6-inch pots and transferred to a greenhouse (with $50 \%$ shade and $65 \%$ humidity).
The percentage of survived plants was calculated after a month of transferring to the greenhouse.

Data analysis. The experimental designs were completely randomized designs for all three experiments. Data from each experiment and the data recorded at 4 and 8 weeks were analyzed separately. Statistical analyses were conducted using statistical software [PROC GLM (SAS version 9.4; SAS Institute, Cary, NC)]. The means were separated using the least significant difference at $P$ $\leq 0.05$ (Khattree and Naik, 2000).

\section{Results}

EXIPT. 1: EVALUATION OF DIFFERENT MEDIA IN JARS. The effect of the medium was significant on most turmeric growth and development characteristics after 4 weeks and on all growth characteristics after 8 weeks of subculture at $P \leq 0.05$. DKW was the best performing medium, followed by the three MS media, and McCown was the worst medium for turmeric (Figs. 1-3). Plants in DKW were the tallest, had the most biomass (fresh weight gain), the highest number of shoot and plantlets, and were the most vigorous [highest growth score (Table 5, Fig. 3)]. On average, the explant's biomass increased by $15.4 \mathrm{~g}$ and produced 18.3 plantlets (shoots with roots) and 30.3 shoots [shoot or shoot primordia without roots (Table 5 )].

Although the DKW was the best medium with the highest number of plantlets (with roots), at the first week of transferring plants to DKW medium, they showed a high salt stress symptoms, such as yellowish leaves (pictures not shown), but they recovered and thrived 1 week later.

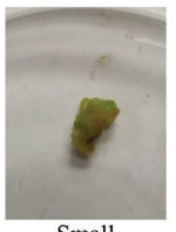

Small

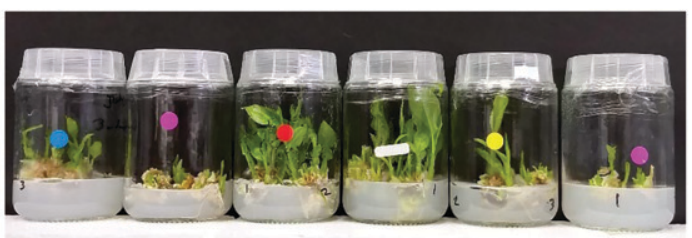

(small primordia)
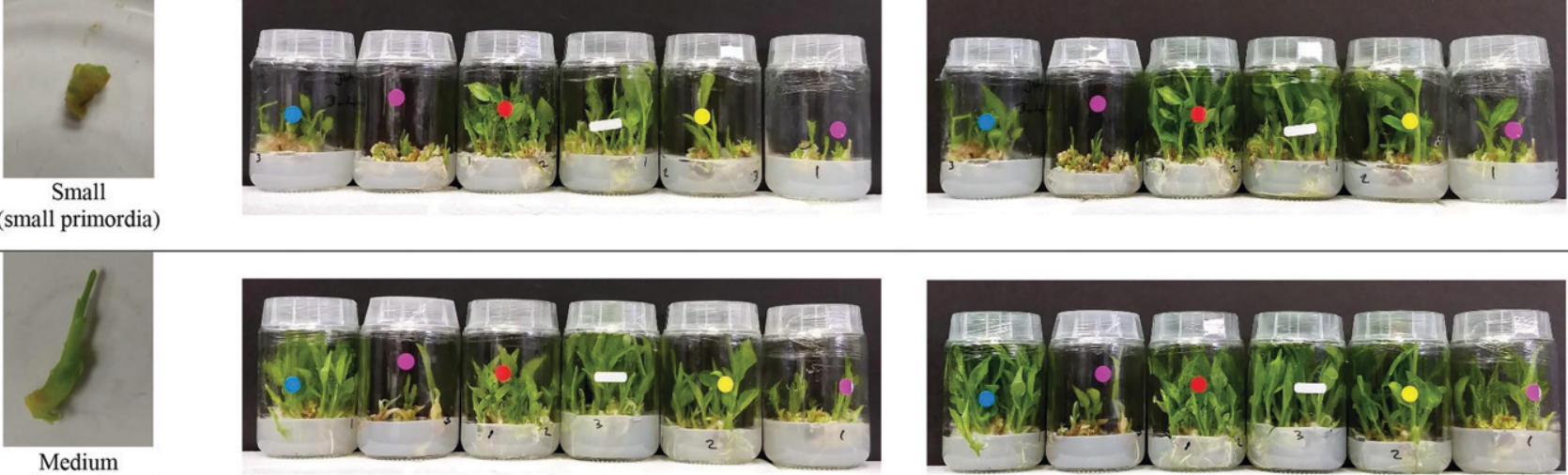

(shoot with tiny leaves)

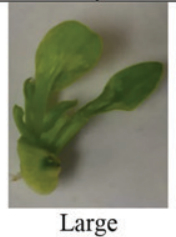

shoot with expanded

leaves, $2 \mathrm{~cm}$ height)
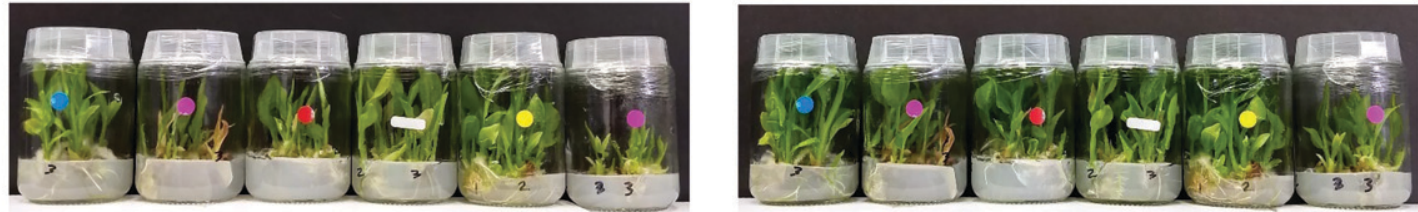

Fig. 1. First experiment of turmeric tissue culture (evaluation of five different media in jars) after 4 weeks. From left, the size of original explant (with no scale, first column), plant growth and development after 4 weeks (second column) and 8 weeks (third column) after subculture. The media were color-coded. From left to right, blue (Murashige and Skoog basal, M5519; Sigma-Aldrich, St. Louis, MO), pink (McCown woody plant basal salt mixture; Sigma-Aldrich, filtered cap), red (Murashige and Skoog basal salt mixture, M5524; Sigma-Aldrich), white (Driver and Kuniyuki walnut; PhytoTech Laboratories, Lenexa, KS), yellow (Murashige and Skoog basal with Gamborg's vitamins, M0404; Sigma-Aldrich), pink (McCown woody plant basal salt mixture, nonfiltered cap); $1 \mathrm{~cm}=0.3937$ inch. 

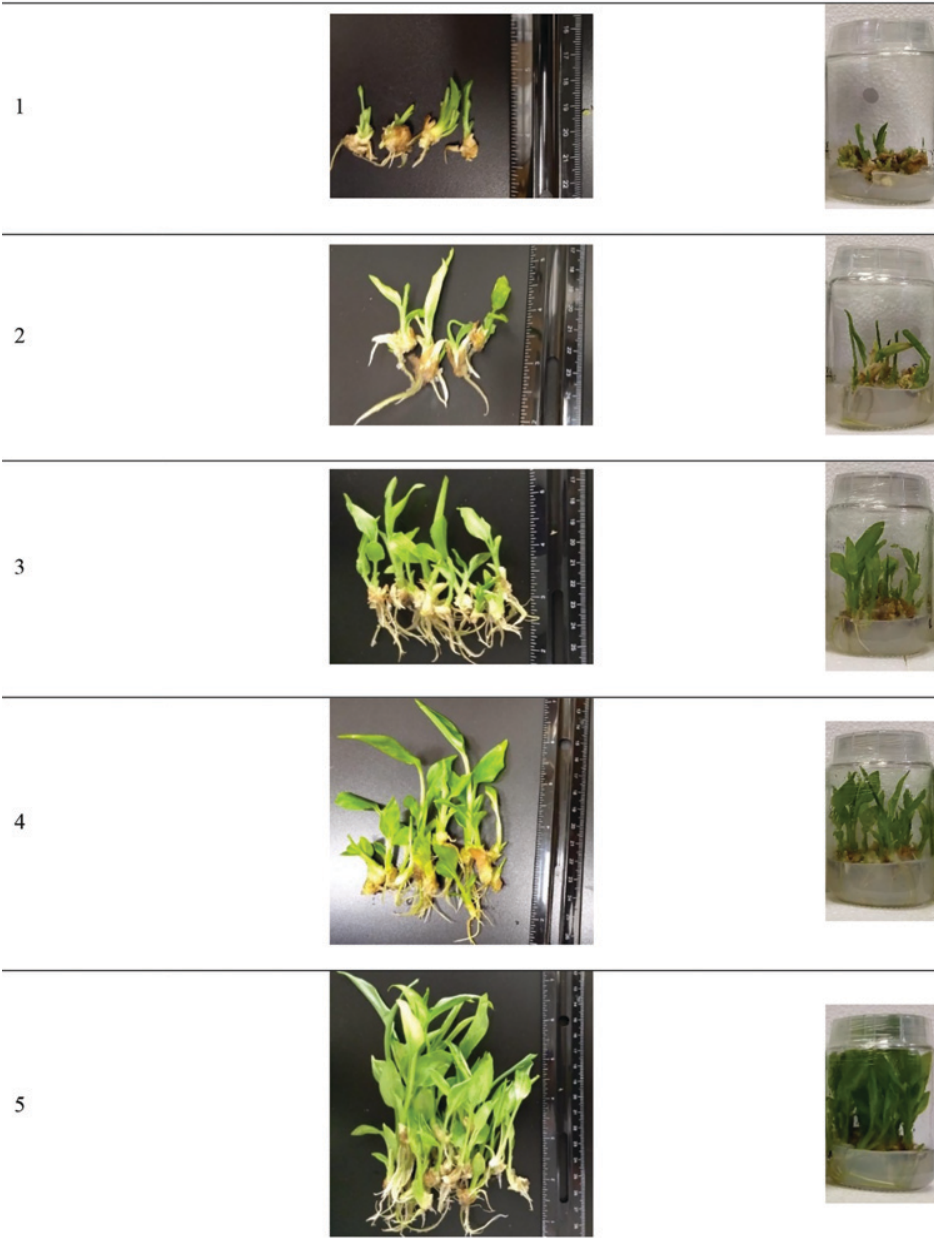

Fig. 2. Growth score of turmeric plants 8 weeks after subculture in the first experiment (evaluation of five different media in jars). Pictures on the left column: All plant material was harvested. Plantlets were scored based on the highest length, $1=1-20 \mathrm{~mm} ; 2=21-40 \mathrm{~mm} ; 3=41-60 \mathrm{~mm} ; 4=61-80 \mathrm{~mm}$; and $5=$ more than $81 \mathrm{~mm}$. Right column: the same plants inside the jar at harvest time; $1 \mathrm{~mm}=0.0394$ inch.
There were no significant differences among the MS media. All MS media had the same macro- and micronutrients, but differed in vitamins. M0404 lacks myo-inositol, while M5524 does not have vitamins in its

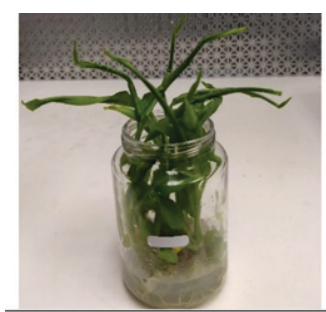

A

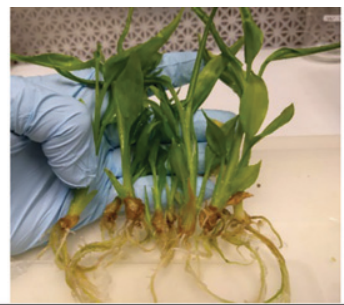

B

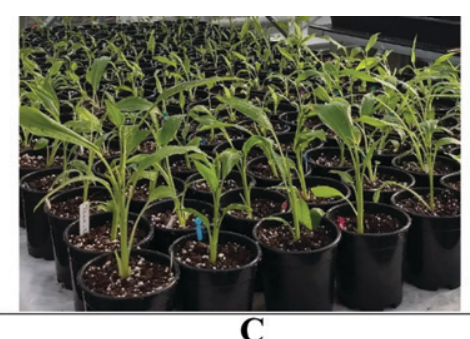

C
Fig. 3. (A) A sample from the best treatments used in the first experiment of turmeric tissue culture (evaluation of five different media in jars) after 8 weeks from the subculture. The treatments were large explants (shoots with about 20 $\mathrm{mm}$ length and expanded leaves) and Driver and Kuniyuki walnut medium (PhytoTech Laboratories, Lenexa, KS). (B) This jar produced 12 plantlets (with roots), and the tallest plant was $167 \mathrm{~mm}$. (C) Three plants of each treatment were transferred to $\mathrm{ex}$ vitro conditions; $1 \mathrm{~mm}=0.0394$ inch. formula, therefore MEM was added to these medium (Table 2). M5519 has lower concentrations of vitamins, and M5524 has different vitamins in its formula than M0404. The differences between vitamins within MS media created some differences in plant growth, but these were not significant.

The McCown medium was used in jars that had caps with and without filters. Plants in McCown medium (nonfiltered and filtered caps) had the lowest growth score and biomass, and those in filtered caps had the lowest number of leaves and roots. We used filtered caps to see if the benefits of facilitated gas exchange and less condensation would benefit the plant growth. To reduce the workload, we randomly selected McCown to test the hypothesis. The filtered caps had higher gas exchange but lost a large amount of water during the experiment (lower weight). The media were cracked at the end of the experiments, and plants looked dried out (Table 5, Figs. 1-3). For all media, larger explants resulted in higher biomass and growth scores and fewer shoots than smaller explants, whereas smaller explants resulted in a greater number of shoots (Table 5, Fig. 1).

The interaction of media and explant size in 4-week-old subcultures showed that medium-sized explants in DKW and McCown had the largest diameter followed by large explants in M5519. The highest number of leaves was recorded in the smallest explants in DKW followed by medium-sized explants in M5519. Smallest explants in M0404 produced the highest number of roots with a large difference from other treatments. Small and mediumsized explants in M5524 and M5519 respectively, produced the highest number of shoots. After 8 weeks of subculture, medium-sized explants in DKW and large and medium-sized explants in M5519 had the highest growth scores. Large and medium-sized explants in M5519 and medium-sized explants in DKW had the largest biomass (data not shown).

EXPT. 2: EVALUATION OF DIFFERENT MEDIA IN CULTURE TUBES. DKW and M0404 media were used as benchmarks in both the first and second experiments (Table 6). As in the first experiment, the DKW produced the tallest plants, the highest biomass (fresh weight gain), and the greatest 


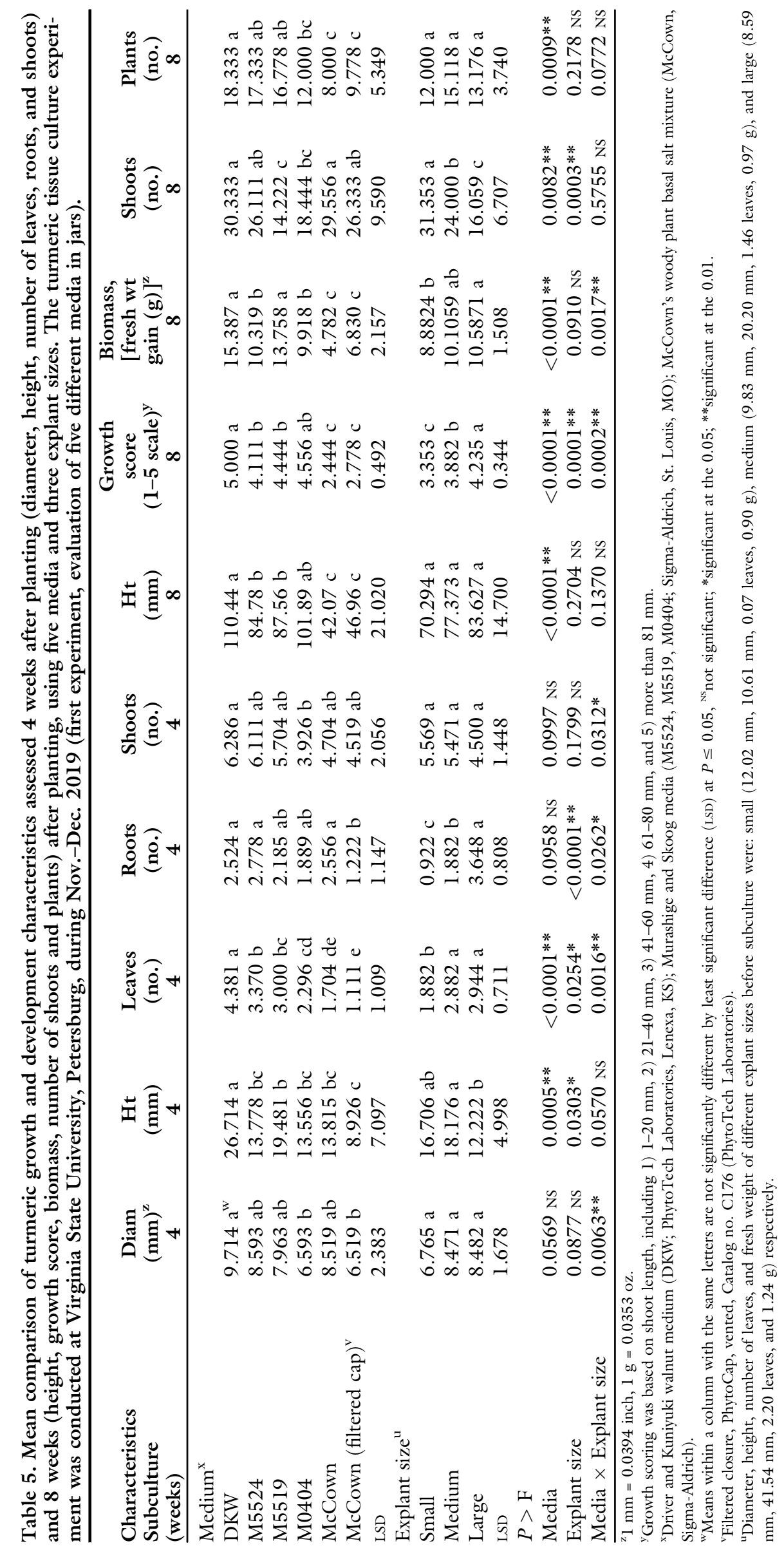


Table 6. Mean comparison of turmeric growth and development characteristics assessed after 8 weeks (height, biomass, number of shoots, and whole plants) using five media. The turmeric tissue culture experiment was conducted at Virginia State University, Petersburg, during Nov. -Dec. 2019 (second experiment; evaluation of different media in culture tubes).

\begin{tabular}{llccc}
\hline Medium $^{\mathbf{z}}$ & Ht $(\mathbf{m m})^{\mathbf{y}}$ & ${\text { Biomass }(\mathbf{g})^{\mathbf{y}}}$ & Shoots (no.) & Plants (no.) \\
\hline DKW & $86.773 \mathrm{a}^{\mathrm{x}}$ & $4.627 \mathrm{a}$ & $14.227 \mathrm{a}$ & $2.136 \mathrm{a}$ \\
M5860 & $60.560 \mathrm{~b}$ & $2.445 \mathrm{~b}$ & $8.640 \mathrm{bc}$ & $1.340 \mathrm{~b}$ \\
BLT & $51.450 \mathrm{~b}$ & $1.637 \mathrm{c}$ & $5.550 \mathrm{c}$ & $2.483 \mathrm{a}$ \\
M0404 & $26.773 \mathrm{c}$ & $1.998 \mathrm{bc}$ & $9.000 \mathrm{~b}$ & $0.318 \mathrm{c}$ \\
L\&M & $22.709 \mathrm{c}$ & $1.575 \mathrm{c}$ & $9.884 \mathrm{~b}$ & $0.116 \mathrm{c}$ \\
LSD & 13.370 & 0.646 & 3.243 & 0.650 \\
P F F & $<0.0001^{* *}$ & $<0.0001^{* *}$ & $<0.0001^{* *}$ & $<0.0001^{* *}$ \\
\hline
\end{tabular}

${ }^{\mathrm{z}}$ Driver and Kuniyuki walnut medium (DKW; Sigma-Aldrich, St. Louis, MO); Murashige and Skoog medium (M5860, M0404; Sigma-Aldrich); broadleaf tree basal medium (BLT; PhytoTech Laboratories, Lenexa, KS); Lloyd \& McCown woody plant basal medium (L\&M, PhytoTech Laboratories).

${ }^{\mathrm{y}} 1 \mathrm{~mm}=0.0394$ inch, $1 \mathrm{~g}=0.0353 \mathrm{oz}$.

${ }^{x}$ Means within a column with the same letters are not significantly different by least significant difference (LSD) at $P \leq 0.01$ and $* *$ significant at $P \leq 0.01$.

number of plants (with roots), and shoots (without roots, $P \leq 0.01$ ). M5860, whose formulation was very similar to M5519, except that it had four times more thiamine hydrochloride, was the second-best medium. When compared with M0404, M5860 promoted a higher number of taller plants. It seems the growth differences were related to the changes in the concentration of vitamins (i.e., thiamine hydrochloride, glycine, etc.). The BLT medium was similar to M5860 in plant height and number of shoots but similar to M0404 in the biomass. BLT and DKW were the best media for the highest number of plants (with roots) but BLT produced the lowest number of shoots (without roots). This medium converted all plant carbohydrates toward the formation of complete plantlets with developed roots (Table 6, Fig. 4). Therefore, if the multiplication rate is not a concern, the BLT medium produced fewer but fully developed plantlets (with roots) than other media. The L\&M medium had the most inferior performance among the five media tested in the second experiment (Table $6)$. Shoots in this medium were small (Fig. 4) and had the fewest number of plantlets (with roots) and biomass.

EXPT. 3: Plant GROWTH REgULATOR MATRIX. The data analysis has shown significant differences between PGRs treatments in the number of shoots, roots, and biomass. Treatment $\mathrm{F}$ with an equal amount of BAP and NAA $\left(0.1 \mathrm{mg} \cdot \mathrm{L}^{-1}\right)$ produced the tallest plants with the highest number of leaves and roots. Treatment $\mathrm{H}\left(2.5 \mathrm{mg} \cdot \mathrm{L}^{-1} \mathrm{BAP}\right.$ and $0.1 \mathrm{mg} \cdot \mathrm{L}^{-1} \mathrm{NAA}$ ) produced the most significant biomass and number of shoots (the highest shoot proliferation) with the lowest number of roots. In this treatment, the cytokinin was at the highest concentration tested, and the lowest concentration of auxin was also present. Treatments with the highest amount of NAA $\left(2.5 \mathrm{mg} \cdot \mathrm{L}^{-1}\right)$ performed the worst (treatments M-P in Table 7 and Fig. 6) with the shortest plants and the lowest number of shoots and leaves. Treatment $\mathrm{L}\left(2.5 \mathrm{mg} \cdot \mathrm{L}^{-1}\right.$ BAP and $1 \mathrm{mg} \cdot \mathrm{L}^{-1}$ NAA), and A (no BAP and NAA) also performed poorly with the lowest diameter, height, number of leaves, root, and shoot proliferation, and biomass.

Adaptation to EX Vitro ENVIRONMENT. The adaptation of plantlets from the three experiments into the ex vitro conditions showed a 97\% survival rate without any significant differences among the experiments or treatments. Therefore, the data are not discussed here.

\section{Discussion}

EFFECT OF MEDIA. Researchers rarely used media other than MS to micropropagate turmeric. Nasirujjaman et al., (2005) found L\&M to be effective in shoot formation, but no comparison was made with MS medium. Prabhakaran Nair (2013) summarized research papers that used Smith (Nadgauda et al., 1978), Ringe and Nitsch (Mukhri and Yamaguchi, 1986), and LS medium (Gayatri et al., 2005). Ma and Gang (2006) used Gamborg's B-5 basal medium with minimal organics. None of these reports compared the media with MS to identify superiority over MS or any other medium as a benchmark.

For example, Gamborg's basal medium produced 10.8 plantlets per explant, but our proliferation rate was $70 \%$ higher, producing 18.3 plants per explant with DKW medium. If a single explant produces 18 plants every 4 weeks ( 1 month), it is possible to produce $18^{1}$, $18^{2}, 18^{3}$ plants at the end of the months 1,2 , and 3 from a single explant. At the end of the year, millions of plants $\left(18^{12}=1.2 \times 10^{15}\right)$ could be produced.

Furthermore, there are no reports on using other media, such as BLT and DKW, on turmeric growth and development under in vitro cultures. In our first two experiments, the DKW was the best medium for 'Hawaiian Red' turmeric with the highest number of complete plantlets (with roots), mainly due to differences in macronutrients such as lower nitrogen and higher sulfate concentrations than MS (Phillips and Garda, 2019; Rahman, 2018). This is evident by the high salt stress symptoms, such as yellowish leaves (pictures not shown) in the first week of transfer to this medium. However, 1 week later the explants recovered and thrived. Although, we have not tested the effectiveness of this medium for other turmeric cultivars, we have used it to micropropagate 'White Mango' turmeric and 'Indira Red' turmeric in our laboratory successfully (T. Taghavi, unpublished data). Because we have not compared DKW with other media, some refinements may be needed for other turmeric cultivars.

Although the macro- and microelements of all MS media were the same, there were minor differences between the media in their vitamin composition and concentration, which was not significant. Thiamine hydrochloride and glycine were the main vitamins changed in the MS media. The minor differences in plant growth, although not significant, may be attributed to differences in vitamins.

BLT medium produced lower biomass than DKW and M5860; however, it was the best medium for producing robust plantlets with higher biomass (had both shoot and root). As far as we know, this is the first report on 1 ) the effect of DKW and BLT on turmeric, and 2) the comparison between MS media with BLT, DKW, and woody plant media, and 3 ) the 


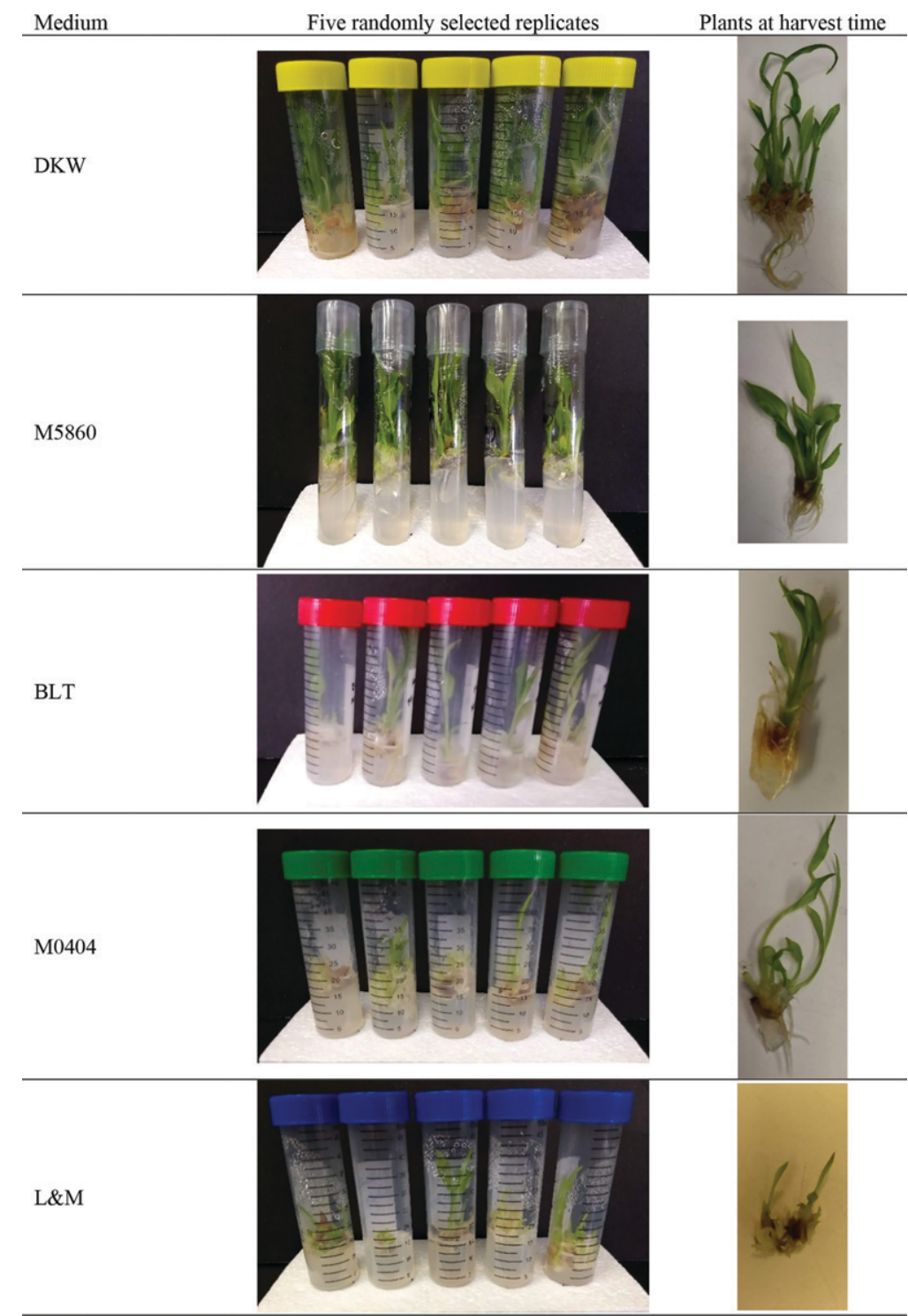

Fig. 4. Left column: the medium [Driver and Kuniyuki walnut (DKW; PhytoTech Laboratories, Lenexa, KS), Murashige and Skoog (MS) multiplication medium (M5860, PhytoTech Laboratories), Broadleaf tree basal (BLT, PhytoTech Laboratories), Murashige and Skoog basal with Gamborg's vitamins (M0404; Sigma-Aldrich, St. Louis, MO), and Lloyd \& McCown woody plant basal with vitamins (L\&M, PhytoTech Laboratories)] used in the second experiment of turmeric tissue culture (five different media in culture tubes). Middle column: five randomly selected replicates were pictured 8 weeks after subculture. Right column: plants harvested 8 weeks after subculture and photographed.

possible roles of vitamins on turmeric growth under in vitro conditions.

The effect of media was more significant than explant size. In the interactioneffect of media and explant size, DKW and M5519 were the best media for most of the characteristics measured. The large explants produced stronger plants (higher diameter, leaves and root numbers), while small explants were superior where more shoot primordia were produced, mainly because less differentiation has happened in small explants and more meristematic cells can convert to shoot primordia.

EFFECT OF PLANT GROWTH REGULATORS. In general, the results confirm that a higher ratio of BAP/ $\mathrm{BA}$ to NAA is needed for shoot formation in turmeric (Roy and Raychaudhuri, 2004). However, the ratio mentioned in the literature covers a very wide range from 1.5 to 100 times higher cytokinin (BA/BAP) than auxin (NAA). It is also unclear if higher concentrations than $3 \mathrm{mg} \cdot \mathrm{L}^{-1}$

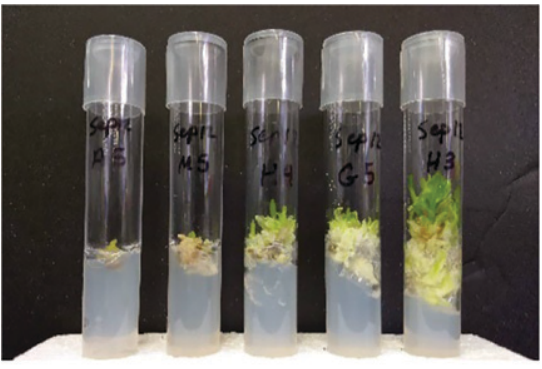

$\begin{array}{lllll}1 & 2 & 3 & 4 & 5\end{array}$

Fig. 5. Shoot proliferation of turmeric was scored based on the growth height (third experiment, evaluating plant growth regulator matrix using Murashige and Skoog (MS) PhytoReady Plant growth Regular Matrix (M6670; PhytoTech Laboratories, Lenexa, KS). Scores were $1=1-10 \mathrm{~mm}, 2=11-20 \mathrm{~mm}$, $3=21-30 \mathrm{~mm}, 4=31-40 \mathrm{~mm}$, and $5=41-50 \mathrm{~mm} ; 1 \mathrm{~mm}=0.0394$ inch .

BAP might reduce shoot multiplication, as there are conflicting results.

Sato et al. (1987) reported that $\mathrm{BAP}$ at rates higher than $1 \mathrm{mg} \cdot \mathrm{L}^{-1}$ induced shoot formation in turmeric, while Balachandran et al. (1990) suggested a concentration of $3 \mathrm{mg} \cdot \mathrm{L}^{-1}$ BAP for shoot multiplication. The report is in agreement with our results that $2.5 \mathrm{mg} \cdot \mathrm{L}^{-1} \mathrm{BAP}$ and $0.1 \mathrm{mg} \cdot \mathrm{L}^{-1}$ NAA were the best combination for shoot multiplication. Salvi et al. (2000) used BA $\left(5\right.$ or $\left.10 \mathrm{mg} \cdot \mathrm{L}^{-1}\right)$ and NAA $\left(0.1 \mathrm{mg} \cdot \mathrm{L}^{-1}\right)$ for direct shoot development, while Rahman et al. (2004) used $2 \mathrm{mg} \cdot \mathrm{L}^{-1}$ BA with $0.1-1 \mathrm{mg} \cdot \mathrm{L}^{-1} \mathrm{NAA}$ for shoot multiplication. Similarly, Nasirujjaman et al. (2005) found that a combination of $4 \mathrm{mg} \cdot \mathrm{L}^{-1}$ of BAP and 1 $\mathrm{mg} \cdot \mathrm{L}^{-1}$ NAA produced the highest number of turmeric shoots. Panda et al. (2007) also used $3 \mathrm{mg} \cdot \mathrm{L}^{-1} \mathrm{BA}$ and 2 $\mathrm{mg} \cdot \mathrm{L}^{-1} \mathrm{NAA}$ for the highest shoot formation. Mohanty et al. (2010) mentioned that number of shoots decreased with increasing BA and NAA concentration above $3 \mathrm{mg} \cdot \mathrm{L}^{-1} \mathrm{BA}$ and 0.5 $\mathrm{mg} \cdot \mathrm{L}^{-1}$ indole-3-acetic acid (IAA). We have not tested higher concentrations than $2.5 \mathrm{mg} \cdot \mathrm{L}^{-1}$ of BAP, but Raihana et al. (2011) used $9 \mathrm{mg} \cdot \mathrm{L}^{-1}$ BAP for a different species of turmeric (Curcuma mangga).

Ghosh et al. (2013) suggested transferring the explants to $2 \mathrm{mg} \cdot \mathrm{L}^{-1}$ indole-3-butyric acid (IBA) for root formation. Our results showed that 0.1 $\mathrm{mg} \cdot \mathrm{L}^{-1} \mathrm{NAA}$ induced root formation 


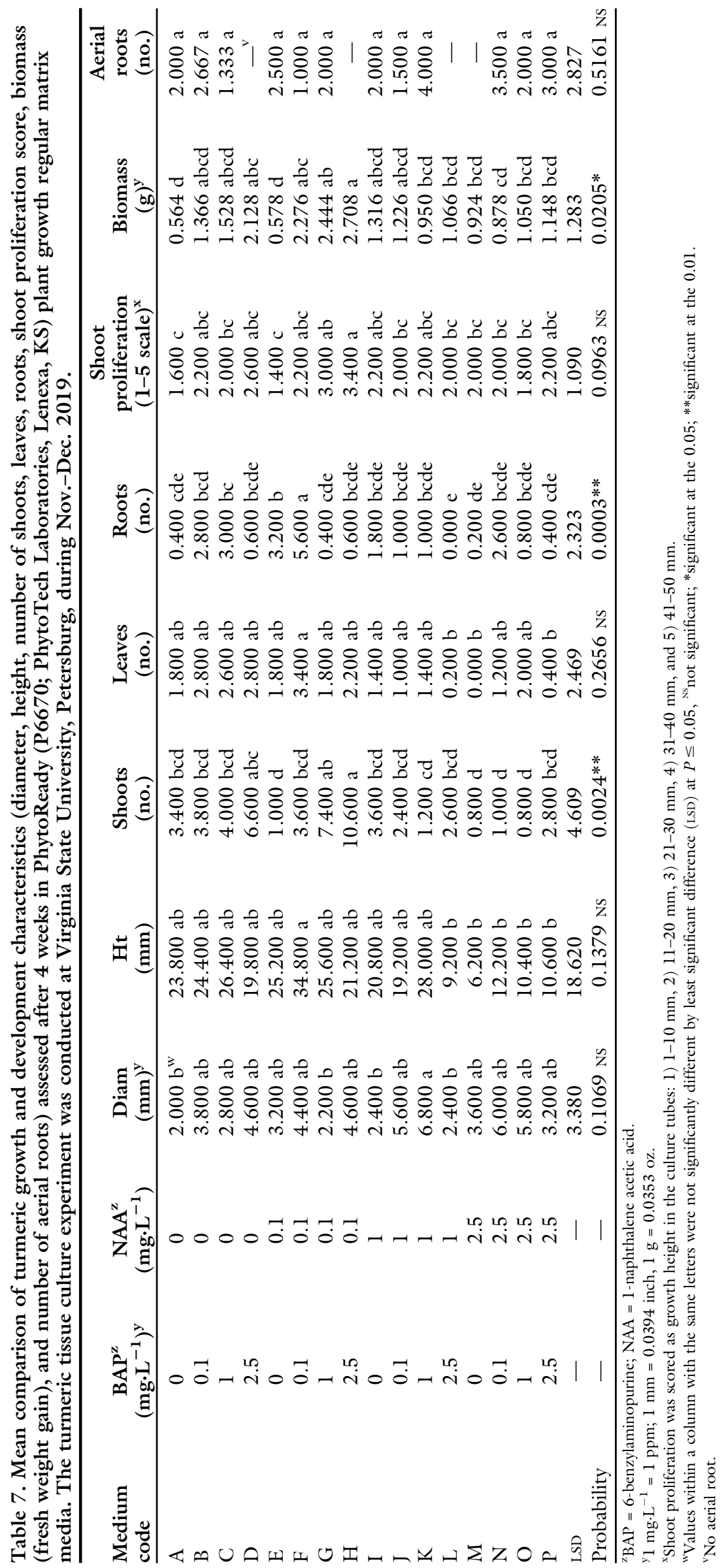

(treatment $\mathrm{E}$ ), but the addition of a low concentration of BAP (treatment F) increased root formation significantly, making it the best treatment for whole plant (with roots) regeneration. Therefore, a low concentration of NAA and $\operatorname{BAP}\left(0.1 \mathrm{mg} \cdot \mathrm{L}^{-1}\right)$ is needed for the highest root formation.

\section{Conclusion}

In conclusion, the DKW medium was the best medium tested and produced the highest number of complete plantlets (with roots), followed by MS media, especially M5860 with different vitamin composition or concentration (i.e., lower amount of Thiamine hydrochloride, 0.1 , compared with $\left.0.4 \mathrm{mg} \cdot \mathrm{L}^{-1}\right)$. On average, 18 plants were produced per explant, which is $70 \%$ higher than the latest reports on turmeric that produced 10.8 plants per explant. The results also suggest that the DKW medium was the best performing medium. Rahman (2018) reported the differences between DKW and MS in their macronutrients composition, since DKW has lower nitrogen and higher sulfate content in its formula (Phillips and Garda, 2019). DKW has the potential to produce millions of turmeric plants within a year, and was the best medium for 'Hawaiian Red' turmeric.

BLT was the third most preferable medium. Although the biomass was not comparable to DKW, produced the highest number of plantlets with robust root systems. The reason is not clear, as several compounds are different between BLT and DKW and M0404. For example M0404 contains more ammonium nitrate than BLT, while BLT has ammonium sulfate, which is lacking in DKW and M0404. Also, calcium nitrate is lacking in M0404 but is available in BLT and DKW. The medium designed for woody plants (L\&M and McCown) did poorly for turmeric tissue cultures. Plants in these media had lower biomass, number of shoots, and roots.

A higher BAP to NAA ratio $(2.5$ $\mathrm{mg} \cdot \mathrm{L}^{-1}$ BAP and $0.1 \mathrm{mg} \cdot \mathrm{L}^{-1} \mathrm{NAA}$ ) was necessary for shoot formation. However, the lowest concentration of both BAP and NAA $\left(0.1 \mathrm{mg} \cdot \mathrm{L}^{-1}\right)$ was the best combination to induce root formation and produce whole plantlets (roots and shoots) without the need for changing the PGRs combination and subsequent subcultures. 


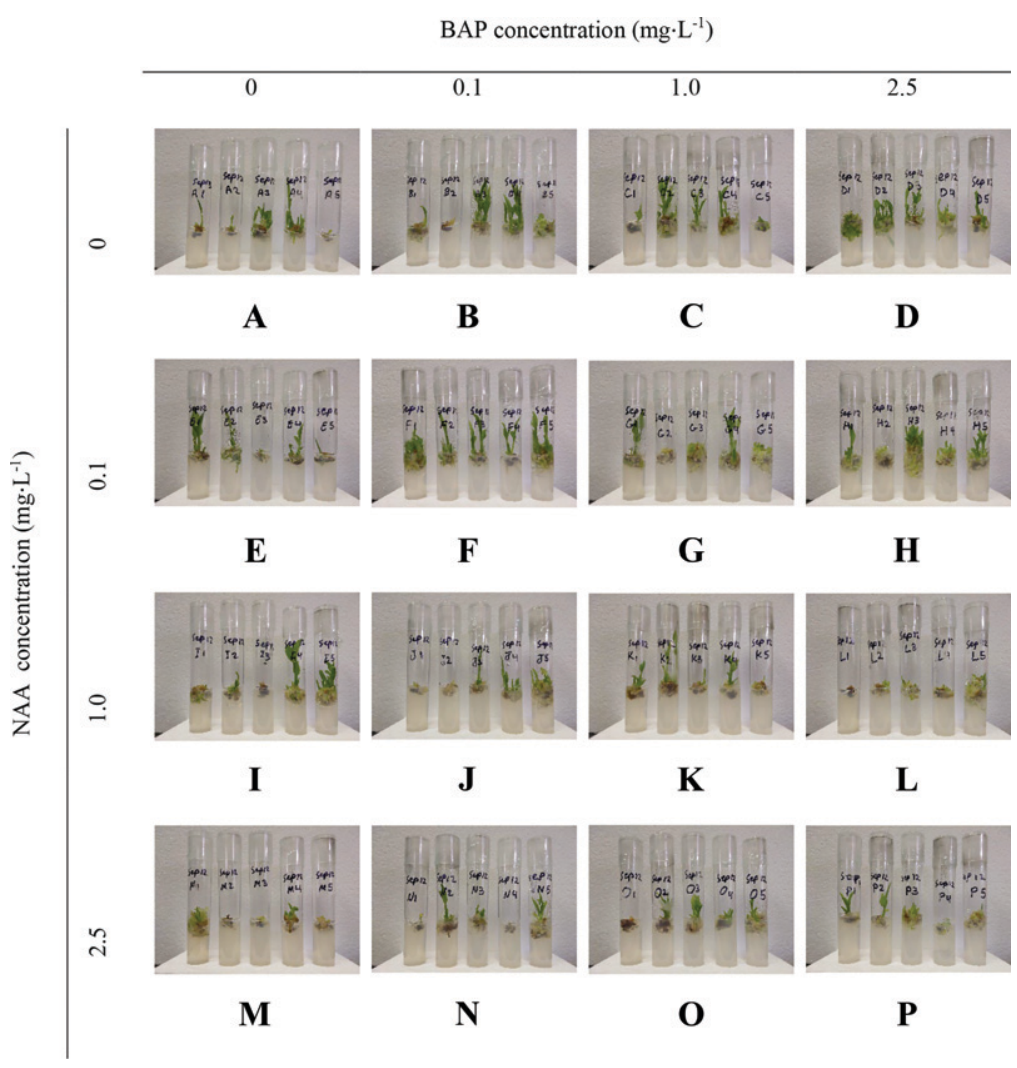

Fig. 6. Small explants of turmeric were cultured in the Murashige and Skoog (MS) PhytoReady plant growth regular matrix (M6670; PhytoTech Laboratories, Lenexa, KS) with a full factorial combination of two plant growth regulators, 6benzylaminopurine (BAP) and 1-naphthaleneacetic acid (NAA) and photographed after 4 weeks; $1 \mathrm{mg} \cdot \mathrm{L}^{-1}=1 \mathrm{ppm}$.

There are two recommendations for tissue culture of 'Hawaiian Red' turmeric. To produce the highest number of plantlets, one should use the higher BAP to NAA ratio $\left(2.5 \mathrm{mg} \cdot \mathrm{L}^{-1}\right.$ BAP and $0.1 \mathrm{mg} \cdot \mathrm{L}^{-1} \mathrm{NAA}$ ) for shoot proliferation and then transfer the explants to the root initiation media. However, to reduce the number of subcultures, the explants can be grown in the lowest concentration of both BAP and NAA $\left(0.1 \mathrm{mg} \cdot \mathrm{L}^{-1}\right)$ to induce both shoot and root. Although the number of plantlets (with roots and shoots) will decrease in this method, there is no need for subsequent subcultures and changing of the PGRs combinations.

\section{Literature cited}

Anoop, K., R. Suseela Bhai, and K.N. Shiva. 2014. Survey on the incidence of rhizome rot disease in major turmeric growing tracts of south India and isolation of associated organisms. Indian J. Adv. Plant. Res. 6(1): 17-23.

Balachandran, S.M., S.R. Bhat, and K.P.S. Chandel. 1990. In vitro clonal multiplication of turmeric (Curcuma spp.) and ginger (Zingiber officinale Rosc.). Plant Cell Rep. 8(9):521-524, https://doi. org/10.1007/BF00820200.

Bhabha Atomic Research Centre. 2020. A rapid, reproducible and sustainable micropropagation protocol for turmeric ( $\mathrm{Cur}^{-}$ cuma longa L.). 13 Oct. 2020. <http:// barc.gov.in/technologies/turmeric/index. html $>$.

Gayatri, M.C., V. Roopadarshini, and R. Kavyashree. 2005. Selection of turmeric callus tolerant to culture filtrates of Pythium graminicolum and regeneration plants. Plant Tissue Organ Cult. 83:33-40, https://doi. org/10.1007/s11240-005-3706-0.

Ghosh, A., P. Chatterjee, and P. Ghosh. 2013. A protocol for rapid propagation of genetically true to type Indian turmeric (Curcuma longa L.) through in vitro culture technique. Adv. Appl. Sci. Res. 4:39-45.

Globe Newswire. 2020. Curcumin market size, share \& trends analysis report by application, by region and segment forecasts, 2020-2027. 13 Oct. 2020. <https:// www.reportlinker.com/p05886335/?utm_ source $=\mathrm{GNW}>$.

Gupta, S.C., S. Patchva, and B.B. Aggarwal. 2013. Therapeutic roles of curcumin:
Lessons learned from clinical trials. Amer. Assoc. Pharm. Sci. J. 15(1):195-218, https://doi.org/10.1208/s12248-0129432-8.

Indian Spice Board Statistics. 2020. Major item/country-wise export of spices from India. 24 July 2020. <http://www.indian spices.com/sites/default/files/Major\%20 Item\%20wise\%20Export\%202020.pdf>.

Khader, M., P. Vedamuthu, and P. Balashanmugam. 1994. Improvement in turmeric, p. 315-332. In: K.L. Chadha and P. Rethinam (eds.). Advances in horticulture. Plantation and spice crops. Malhotra Publishing House, New Delhi, India.

Khattree, R. and D.N. Naik. 2000. Multivariate data reduction and discrimination with SAS software. SAS Inst., Cary, NC.

Kyger, L. 2019. Spicy trade: U.S. and India turn up the heat. 21 Dec. 2020. <https:// tradevistas.org/spicy-trade-us-india-turn-upheat $/>$.

Ma, X. and D.R. Gang. 2006. Metabolic profiling of turmeric (Curcuma longa L.) plants derived from in vitro micropropagation and conventional greenhouse cultivation. J. Agr. Food Chem. 54(25):95739583, https://doi.org/10.1021/jf0616 $58 \mathrm{k}$.

Mohanty, S., R.K. Joshi, E. Subudhi, S. Sahoo, and S. Nayak. 2010. Assessment of genetic stability of micropropagated Curcuma caesia through cytophotometric and molecular analysis. Cytologia (Tokyo) 75: 73-81, https://doi.org/10.1508/cytologia. 75.73 .

Mukhri, Z. and H. Yamaguchi. 1986. In vitro plant multiplication from rhizomes of turmeric (Curcuma domestica Val.) and temoelawak (C. xanthoriza Roxb.). Plant Tissue Cult. Lett. 3:28-30, https://doi.org/ 10.5511/plantbiotechnology1984.3.28.

Murashige, T. and F. Skoog. 1962. A revised medium for rapid growth and bioassay with tobacco tissue cultures. Physiol. Plant. 15(3):473-497, https://doi. org/10.1111/j.1399-3054.1962.tb0 8052.x.

Nadgauda, R.S., A.F. Mascarenhas, R.R. Hendre, and V. Jagannathan. 1978. Rapid multiplication of turmeric (Curcuma longa L.) plants by tissue culture. Indian J. Exp. Biol. 16:120-122.

Nasirujjaman, K., M. Salah-Uddin, S. Zaman, and M.A. Reza. 2005. Micropropagation of turmeric (Curcuma longa Linn.) through in vitro rhizome bud culture. J. Biol. Sci. 5(4):490-492, https:// doi.org/10.3923/jbs.2005.490.492.

Nowak, J. and K. Pruski. 2004. Priming tissue cultured propagules, p. 68-81. In: Joint 
FAO (ed.). Low cost options for tissue culture technology in developing countries. Proceedings of a technical meeting (No. IAEA-TECDOC-1384). Joint FAO/IAEA Division of Nuclear Techniques in Food and Agriculture. 24 July 2020. <https://wwwpub.iaea.org/mtcd/publications/pdf/te_ 1384_web.pdf >.

Panda, M.K., S. Mohanty, E. Subudhi, L. Acharya, and S. Nayak. 2007. Assessment of genetic stability of micropropagated plants of Curcuma longa L. by cytophotometry and RAPD analysis. Intl. J. Integr. Biol. $1(3): 189-195$.

Phillips, G. and M. Garda. 2019. Plant tissue culture media and practices: An overview. In Vitro Cell. Dev. Biol. Plant 55(3):242257, https://doi.org/10.1007/s11627019-09983-5.

Lloyd, G. and B. McCown. 1981. Commercially feasible micropropagation of mountain laurel, Kalmia latifolia by shoot tip culture. Intl. Plant. Prop. Soc. Proc. 30:421-427.

Prabhakaran Nair, K.P. 2013. The agronomy and economy of turmeric and ginger. Elsevier, Amsterdam, The Netherlands.

Rafie, R. and C. Mullins. 2017. Ginger and turmeric production. A presentation on ginger and turmeric field day on 16 Nov. 2017, Virginia State University. 24 July 2020. <http://www.vsuag.net/wp-content/ uploads $/ 2017 / 11 /$ Ginger-and-TurmericPresentation-2017-B-Dr-Rafie-SM-1.pdf $>$.

Rahman, S.S. 2018. DKW emerges as a superior media factor in vitro plant regeneration. J. Agr. 1(1):3-4.

Rahman, M.M., M.N. Amin, H.S. Jahan, and R. Ahmad. 2004. In vitro regeneration of plantlets of Curcuma longa Linn. A valuable spice plant in Bangladesh. Asian J. Plant Sci. 3(3):306-309, doi: https://doi. org/10.3923/ajps.2004.306.309.

Raihana, R., Q.Z. Faridah, A.A. Julia, A.H.A. Abdelmageed, and M. Abdul Kadir. 2011. In vitro culture of Curcuma mangga from rhizome bud. J. Med. Plants Res. 5(28):6418-6422, https://doi.org/ 10.5897/JMPR11.673.

Ravindran, P.N., K.N. Babu, and K. Sivaranan. 2007. Turmeric: The genus Curcuma. CRC Press, Boca Raton, FL.

Roy, S. and S.S. Raychaudhuri. 2004. In vitro regeneration and estimation of curcumin content in four species of Curcuma. Plant Biotechnol. 21(4):299-302, https:// doi.org/10.5511/plantbiotechnology.21. 299.

Salvi, N.D., L. George, and S. Eapen. 2000. Direct regeneration of shoots from immature inflorescence cultures of turmeric. Plant Cell Tissue Organ Cult. 62: 235-238, https://doi.org/10.1023/A: 1006459822879 .

Sasikumar, B. 2005. Genetic resources of Curcuma: Diversity, characterization and utilization. Plant Genet. Res. 3(2):230-251, https://doi.org/10.1079/PGR200574.

Sato, M., M. Kuroyanagi, A. Ueno, K. Shimomura, and M. Satake. 1987. Plant tissue culture of Zingiberaceae (II) In vitro propagation of turmeric (Curcuma longa Linn.). Plant Tissue Cult. Lett. 4(2):86-88, https://doi.org/10.5511/ plantbiotechnology1984.4.86.

Shagufta, N., I. Saiqa, J. Sumera, and A. Amir. 2009. In vitro clonal multiplication and acclimatization of different varieties of turmeric (Curcuma longa L.). Pak. J. Bot. 41(6):2807-2816.

Shirgurkar, M.V., C.K. John, and R.S. Nadgauda. 2001. Factor affecting in vitro microrhizome production in turmeric. Plant Cell Tissue Organ Cult. 64:5-11, https://doi.org/10.1023/A:101064562 4618.

Sinchana, N.S., K.N. Kattimani, G. Prabhuling, K. Sudesh, and N. Jagadeesha. 2020. Standardization of tissue culture protocol for turmeric (Curcuma longa L.) cv. Salem. Intl. J. Chem. Stud. 8(1):2721-2726, https://doi.org/10.22271/chemi.2020.v8. ilao.8681.

Sit, A.K. and R.S. Tiwari. 1996. Micropropagation in turmeric (C. longa). Souvenir National Symposium on Horticulture and Biotechnology, Bangalore, India, 28-30 Oct. 1996, p. 23.

Sugaya, A. 1992. Micropropagation of turmeric (Curcuma domestica Valet) and other Curcuma species, p. 277-294. In: Y.P.S. Bajaj (ed.). Biotechnology in agriculture and forestry: High-tech and micropropagation III. Springer-Verlag, Berlin, Germany, doi: https://doi.org/10.1007/ 978-3-662-07770-2_17.

Verma, R.K., P. Kumari, R.K. Maurya, V. Kumar, R.B. Verma, and R.K. Singh. 2018. Medicinal properties of turmeric (Curcuma longa L.): A review. Intl. J. Chem. Stud. 6(4):1354-1357.

Wu, K., X. Zhang, S. Sun, and X. Wang. 2015. Factors affecting the accumulation of curcumin in microrhizomes of Curcuma aromatica Salisb. BioMed Res. Intl. 2015: 1-10, https://doi.org/10.1155/2015/ 740794 . 